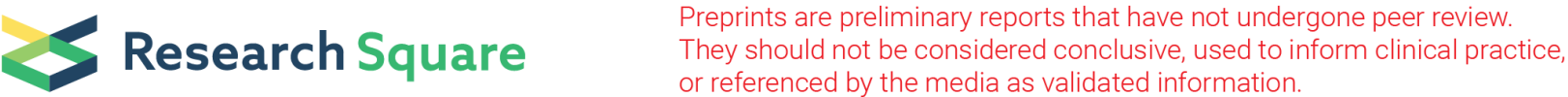

\section{Right Ventricular Function during Trastuzumab Therapy for Breast Cancer}

Geris Mazzutti ( $\square$ gmazzutti@hcpa.edu.br)

HCPA: Hospital de Clinicas de Porto Alegre https://orcid.org/0000-0002-9521-5017

Fernando Pivatto Júnior

HCPA: Hospital de Clinicas de Porto Alegre

Guilherme Oliveira Magalhães Costa

HCPA: Hospital de Clinicas de Porto Alegre

Andreia Biolo

HCPA: Hospital de Clinicas de Porto Alegre

Angela Barreto Santiago Santos

HCPA: Hospital de Clinicas de Porto Alegre

\section{Research Article}

Keywords: Breast Cancer, Cardiotoxicity, Trastuzumab, Myocardial strain, Right ventricular

Posted Date: July 30th, 2021

DOI: https://doi.org/10.21203/rs.3.rs-721985/v1

License: (c) (1) This work is licensed under a Creative Commons Attribution 4.0 International License. Read Full License

Version of Record: A version of this preprint was published at The International Journal of Cardiovascular Imaging on November 16th, 2021. See the published version at https://doi.org/10.1007/s10554-02102470-2. 


\section{Abstract}

Purpose

Cardiotoxicity (CDT) is the main adverse effect related to trastuzumab (TTZ) use, and the role of the right ventricle (RV) in this context is not clear. We aimed to evaluate the longitudinal changes in RV function during TTZ therapy and to determine the differences in RV function associated with subclinical CDT.

Methods

Patients with breast cancer underwent echocardiograms at the beginning of TTZ treatment (Ex 1) and every 3 months during the first year $(E x 2,3,4)$. Subclinical CDT was defined as $\geq 12 \%$ relative reduction of left ventricle global longitudinal strain (LV GLS).

Results

Twenty-five women $(52.1 \pm 13.1 \mathrm{y}-0)$ were included. We found a decrease in LV ejection fraction between the first and fourth exams and the LV GLS gradually decreased during follow-up (Ex1: $-20.6 \pm 2.0$; Ex2: $-19.4 \pm 2.1$; Ex3: $-19.2 \pm 1.8$; Ex4: $-19.0 \pm 2.1$, all $p<0.05$ ). RV GLS changed from baseline to 3 month and to 6 month (Ex1: $-23.9 \% \pm 1.6$; Ex2: $-22.5 \% \pm 2.1$; Ex3: $-22.5 \% \pm 2.3$, all $p<0.05$ ), and the RV Fractional Area Change was lower in the third exam (Ex1: $44.3 \% \pm 6.6$ vs Ex3: $39.9 \% \pm 6.0, p=0.004$ ). We found subclinical CDT in 13 patients (52\%); changes in RV parameters had the same pattern of changing in the group with and without subclinical CDT.

Conclusion

In this sample, the RV function decreased during TTZ therapy and the decrease was not associated to the observed LV cardiotoxicity.

\section{Introduction}

The number of cancer treatment survivors is increasing over the past few decades. Adverse cardiovascular effects during and after chemotherapy are revealed to be one of the biggest challenges of cancer patients treatment due to the possibility of compromising the optimal oncological therapy, and by the association with permanent cardiovascular damage and mortality. The spectrum of cardiotoxicity involves from transient and asymptomatic cardiac changes, to permanent structural damage and heart failure. Traditional chemotherapy drugs, as anthracyclines, and new treatments, as target therapies and immunotherapies, are related to cardiotoxicity. 2,3 Trastuzumab, a monoclonal antibody that blocks the human epidermal growth factor receptor type 2 (HER2), significantly improves survival in HER2-positive breast cancer, but it has been associated with the development of left ventricular dysfunction.'

Current international guidelines recommended monitoring left ventricle(LV) systolic function during trastuzumab therapy, establishing parameters for treatment interruption or modification when there is a 
reduction in the left ventricular ejection fraction (LVEF). ${ }^{2}$ The search for early diagnosis and cardiotoxicity prevention, before theLVEF changes, remains one of the main objectives of Cardio-Oncology. New echocardiographic technique such as left ventricle global longitudinal strain (LV GLS)allows to detect subclinical LV dysfunction that would be undetectable by traditional measures on echocardiogram. LV GLS predicts outcomes in different scenarios such as valvopathies and cardiomyopathies' anda reduced LV GLS has been shown to be a predictor of anthracycline-cardiotoxicity, and the recent guidelines incorporated these data in order to detect subtle changes in LV function. ${ }^{7}$ However, the right ventricle (RV) was less studied in the context of Cardio-Oncology. Recent studies demonstrated changes on the RV structure and function reduction during cancer treatment, especially after protocols with anthracyclines

and trastuzumab. ${ }^{5}$ Also, reduced RV functionwas associated with the development of symptoms such as dyspnea after treatment for breast cancer. Pathophysiological mechanisms, such as fragile structure, thinner wall thickness and fewer number of myofibrils, have been described as potential factors related to the greater sensitivity of RV to cardiotoxicity related to cancer treatment.

We aimed to evaluate the longitudinal changes in RV function during trastuzumab therapy and to determine if RV function change is associated with subclinical LV cardiotoxicity detected by LV GLS.

\section{Methods}

\section{Study Population}

We prospectively selected patients at the Hospital de Clínicas de Porto Alegre (HCPA), a Brazilian tertiarycare teaching hospital, from June 2019 to May 2020. Inclusion criteria were age $\geq 18$ years; diagnosis of early HER2- positive breast cancer (stage I-III) with treatment plan to use trastuzumab. Patients with current or previous heart failure; baseline LVEF $<55 \%$; significant valvopathy, hypertrophic cardiomyopathy, infiltrative cardiomyopathy, estimated glomerular filtration rate (eGFR) $<30 \mathrm{~mL} / \mathrm{min} / 1.73$ $\mathrm{m}^{2}$ ) or cirrhose were excluded. The study protocol was approved by the HCPA ethics committee (IRB approval 2019-0010) and all patients signed an informed consent form. The patients underwent echocardiograms at the beginning of trastuzumab treatment of HER2 positive breast cancer (Exam 1) and subsequently every 3 months during the first year (Exam 2, 3 and 4). Out of the 28 screened patients, 25 were included in this analysis with a completed 1 year-follow up.

\section{Echocardiography analysis}

All echocardiograms were recorded and analyzed offline on a TOMTEC workstation (TomTec ImagingSystems, Unterschleißheim, Germany) by an experienced echocardiographer (GM), blinded to clinical data. Measurements were obtained according to American Society of Echocardiography (ASE) standards, including septal and posterior wall thicknesses; diameters of the LV, RV, aorta, and left atrium; transmitral flow; mitral and tricuspid annular relaxation velocities; and tricuspid annular excursion.

Echocardiographic measures of RV function were performed using the RV-focused apical 4-chamber view. Tricuspid annular plane systolic excursion (TAPSE) was measured as the vertical displacement of 
the tricuspid annulus from end-diastole to end-systole using M-mode. The tissue Doppler-derived tricuspid lateral annular systolic velocity wave ( $\mathrm{S}$ wave) was obtained aligning the basal segment and the tricuspid annulus with the Doppler cursor. Analysis of myocardial deformation (GLS) was performed using specific B-mode speckle-tracking software for the LV and the RV (2D CPA TTA2.20.01, TomTec). This software circumvents angle dependency and identifies cardiac motion by tracking multiple reference points over time. At end-systole, as defined by ECG, three landmarks were established the endocardial edge (two basal and one apical), with automatic detection of speckles along the endocardial edge of the specified cavity (LV or RV). Manual adjustments were made when necessary. In the LV, peak-systolic strain for each 2D apical view (two-, three-, and four-chamber) was automatically obtained from the mean of the 6 traced segments, while LV GLS was obtained by averaging the peak-systolic strain of apical views. Subclinical cardiac dysfunction related to cancer treatment (GLS-CDRCT) was defined as a relative reduction from the baseline LV GLS of $\geq 12 \%$ at any follow-up time point, based on the SUCCOUR trial. In the RV, RV GLS was defined as the peak-systolic strain that combined the free wall and the septum (Fig. 1). All patients were in sinus rhythm, and a single cardiac cycle was analyzed. Images in which poor quality precluded speckle analysis in two or more consecutive segments, images covering less than one complete cardiac cycle, or excessively tangential views were excluded. RV end-systolic and end-diastolic areas were used to derive other measures of myocardial function, such as RV Fractional Area Change (RV FAC).

Intraobserver variability for LV GLS and RV GLS was assessed in a sample of 20 randomly selected echocardiograms. The coefficient of variation was $5.5 \%$ and $4.5 \%$ for LV GLS and RV GLS, respectively. Intraclass correlation coefficients were 0.95 for LV GLS (95\% Cl: $0.90-0.99)$ and 0.95 for RV GLS (95\% Cl: 0.90-0.99).

\section{Statistical analysis}

Continuous variables are displayed as mean \pm standard deviation (SD) or median (interquartile range), and categorical data are shown as total sample and proportion. Mean values were compared between groups using Student's t-test for continuous variables or test $X^{2}$ for categorical variables. Wilcoxon ranksum test was used to compare eGFR, which were expressed as median values with interquartile ranges. To assess longitudinal changes of the values of the echocardiographic parameters assessed, we used repeated measures analysis of variance (ANOVA), considering the p-value from the F-test of Huynh-Feldt and followed by a post hoc analysis. To compare the differences in longitudinal changes of the RV echocardiographic parameters between the groups, we used mixed linear regression models followed by parallelism test to obtain the $p$-value and a post hoc analysis. All statistical analyses were performed with the STATA software package (version 12; Stata, College Station, TX). All tests were 2-sided and P values of $<0.05$ were considered statistically significant.

\section{Results}


The clinical characteristics of the study population are shown in Table 1. All patients included in the study $(n=25)$ were female, with a mean age of $52.1 \pm 13.1$ years. The prevalence of hypertension was $32 \%$, under treatment with angiotensin-converting enzyme inhibitors in $20 \%$ and with beta-blockers in $20 \%$. Twenty-one (84\%) patients had been treated with radiotherapy and $46 \%$ also used anthracyclines (doxorubicin total dose of $240 \mathrm{mg} / \mathrm{m}^{2}$ ). None of the patients had significant heart valve disease, ischemic heart disease or renal failure.

Mean values of echocardiographic parameters of the baseline and follow-up exams are shown in Table 2.During the follow-up period, LVEF significantly reduced in the last exam compared with the baseline (Ex1: $64.1 \% \pm 4.9$ vs Ex4: $60.9 \% \pm 4.9, p=0.003$ ), while the LV GLS decreased progressively in each follow-up exam compared to the baseline value (Ex1: $-20.6 \% \pm 2.0 ;$ Ex2: $-19.4 \% \pm 2.1$, Ex3: $-19.2 \% \pm$ 1.8 and Ex4: $-19.0 \% \pm 2.1$, all $p<0.05)$. Regarding the RV parameters, RV GLS decreased in the first two follow-up exams (Ex1:-23.9\% \pm 1.6 vs Ex2: $-22.5 \% \pm 2.1 p=0.02$ and Ex1: $-23.9 \% \pm 1.6$ vs Ex3:-22.5\% \pm 2.3 $p=0.01$ ) and the RV FAC was lower in the third exam (Ex1: $44.3 \% \pm 6.6$ vs Ex3: $39.9 \% \pm 6.0, p=0.004$ ) compared to the baseline exam (Fig. 2). The RV dimension, TAPSE and S wave did not differ during the chemotherapy period.

Of the 25 patients, only one of these had LVEF criteria for cardiotoxicity, defined by LVEF decrease of > $10 \%$ to a value $<53 \%$. However, we found that 13 of the 25 patients in our study (52\%) presented subclinical LV cardiotoxicity (GLS-CDRCT). At baseline, patients with GLS-CDRCT had larger LV dimensions compared to patients without GLS-CDRCT, but most of the clinical and echocardiographic variables were similar between the two groups (Table 3 and Table 4). During the trastuzumab treatment, $\mathrm{RV}$ dimensions and function had a similar temporal pattern with similar values between the groups with and without GLS-CDRCT (Table 5), including the parameters that changed over the follow up time (RV GLS and RV FAC). (Fig. 3).

\section{Discussion}

In our study, we observed that RV FAC and RV GLS reduced at around 6 months of trastuzumab treatment, with no changes in RV dimension and other parameters of RV function. Our sample had a low incidence of clinical cardiotoxicity, with $52 \%$ of subclinical GLS-CDRCT, and we found no differences in RV dimension and RV function, including RV FAC and RV GLS, associated to the observed LV cardiotoxicity.

Although the established evidence of the impact of trastuzumab therapy in LV function, ${ }^{7}$, the influence of this cancer treatment in the RV function is less well understood. Similarly to Lange et al. ${ }^{17}$ and Calleja et al., ${ }^{18}$ our data reinforced the presence of impairment RV function during trastuzumab therapy - not by traditional echocardiographic measures as TAPSE and S'wave - but based on reduced RV FAC and RV GLS at 6 months treatment.' The RV FAC, such as RV GLS, seems to provide a better accurate measure of $\mathrm{RV}$ function compared to the gold standard magnetic resonance imaging besides that myocardial strain provided a more robust technique for the detection of subclinical myocardial dysfunction. Keramida et 
al. ${ }^{19}$ found that a percent change of $-14.8 \%$ of RV GLS predicted cardiotoxicity in breast cancer treatment with $66.7 \%$ sensitivity and $70.8 \%$ specificity, a cut-off similar to the percent change of LV GLS to predict cardiotoxicity. ${ }^{15}$ Although, the function of the $\mathrm{RV}$ is recognized to be an important prognostic indicator in heart disease and one of the main factors associated with the exercise capacity and development of dyspnea in patients with heart failure, the prognostic implication of RV dysfunction associated with trastuzumab therapy remains to be determined.

The low incidence of clinical cardiotoxicity based on LVEF reduction in our sample (only 1 patient out of 25 total sample size) can be related to the lower anthracycline using compared to others studies, ${ }^{19}$, since the cardiotoxicity incidence reported in previous studies was $3-7 \%$ of patients who received trastuzumab without anthracyclines, reaching around $30 \%$ in trastuzumab and anthracyclines combined treatment. However, half of our sample (52\%) presented subclinical GLS-CDRCT, detected by decreased of LV-GLS. In this early stage of LV dysfunction, we could not identify subtle changes in RV function associated to the presence or not of subclinical GLS-CDRCT, as were observed in studies with LVEF reduction CDT. ${ }^{19,26}$ This findings are aligned with Keramida et al., where LV GLS is significantly decreased earlier than RV GLS in cancer treatment. The mechanism behind that is unknown, but it may justify the role of LV GLS in identifying subclinical cardiotoxicity in advance. ${ }^{19}$

Our results must be interpreted cautiously. The single-center design, our relatively small sample size and the low incidence of clinical cardiotoxicity, defined by decreased LV ejection fraction, are limitations to be considered.

\section{Conclusion}

In this sample of TTZ treated patients, with a low prevalence of LV cardiotoxicity as defined by LVEF reduction, the RV function decreased during the trastuzumab therapy, and the RV changes were not associated to subclinical LV cardiotoxicity. The prognostic value of deterioration of RV during the TTZ therapy needs further studies.

\section{Abbreviations}

ASE, American Society of Echocardiography; CDRCT, cardiac dysfunction related to cancer treatment; GLS, global longitudinal strain; HCPA, Hospital de Clínicas de Porto Alegre; HER2, human epidermal growth factor receptor type 2; LVEF, left ventricular ejection fraction; LV, left ventricular; SD, standard deviation; TAPSE, tricuspid annular plane systolic excursion; RV, right ventricle; RV FAC, right ventricle fractional area change; eGRF, estimated glomerular filtration rate; ACEI/ARB, angiotensin-converting enzyme inhibitors/angiotensin receptor blockers.

\section{Declarations}

Conflict of Interest: The authors declare no conflict of interest. 
Funding: This study was partially financed by the Coordination for the Improvement of Higher Education (CAPES- Brazil) - Finance Code 001, and Research Incentive Fund/Research and Postgraduate Group (FIPE/GPPG CEP 2019-0010) of the Hospital de Clínicas de Porto Alegre, Rio Grande do Sul, Brazil.

Ethical approval: All procedures performed in the present study were in accordance with the ethical standards of the institutional research committee and with the 1964 Helsinki declaration and its later amendments or comparable ethical standards.

Informed consent: Informed consent was obtained from all individual participants included in the study.

\section{Author's contribution:}

GM, FPJ, AB and ABSS were responsible for the conception and design of the study.

GM, FPJ and GOM performed the data collection.

GM and ABSS were responsible for the analysis, and interpretation of data, and for drafting the manuscript.

FPJ and $A B$ were responsible for critically revising the manuscript for important intellectual content.

All authors have read and given final approval of the submitted manuscript.

\section{References}

1. Miller KD, Siegel RL, Lin CC, Mariotto AB, Kramer JL, Rowland JH, Stein KD, Alteri R, Jemal A (2016) Cancer treatment and survivorship statistics, 2016. CA: a cancer journal for clinicians, 66(4), 271289. https://doi.org/10.3322/caac.21349

2. Alexandre J, Cautela J, Ederhy S, Damaj GL, Salem JE, Barlesi F, Farnault L, Charbonnier A, Mirabel M, Champiat S, Cohen-Solal A, Cohen A, Dolladille C, Thuny F (2020) Cardiovascular Toxicity Related to Cancer Treatment: A Pragmatic Approach to the American and European Cardio-Oncology Guidelines. Journal of the American Heart Association, 9(18), e018403. https://doi.org/10.1161/JAHA.120.018403

3. Chen J, Long JB, Hurria A, Owusu C, Steingart RM, Gross CP (2012) Incidence of heart failure or cardiomyopathy after adjuvant trastuzumab therapy for breast cancer. Journal of the American College of Cardiology, 60(24), 2504-2512. https://doi.org/10.1016/j.jacc.2012.07.068

4. Piccart-Gebhart MJ, Procter M, Leyland-Jones B, Goldhirsch A, Untch M, Smith I, Gianni L, Baselga J, Bell R, Jackisch C, Cameron D, Dowsett M, Barrios CH, Steger G, Huang CS, Andersson M, Inbar M, Lichinitser M, Láng I, Nitz U, Herceptin Adjuvant (HERA) Trial Study Team (2005) Trastuzumab after adjuvant chemotherapy in HER2-positive breast cancer. The New England Journal of Medicine, 353(16), 1659-1672. https://doi.org/10.1056/NEJMoa052306 
5. Tadic M, Cuspidi C, Hering D, Venneri L, Danylenko O (2017) The influence of chemotherapy on the right ventricle: did we forget something?. Clinical cardiology, 40(7), 437-

443. https://doi.org/10.1002/clc.22672

6. Guglin M, Cutro R, Mishkin JD (2008) Trastuzumab-induced cardiomyopathy. Journal of cardiac failure, 14(5), 437-444. https://doi.org/10.1016/j.cardfail.2008.02.002

7. Curigliano G, Lenihan D, Fradley M, Ganatra S, Barac A, Blaes A, Herrmann J, Porter C, Lyon AR, Lancellotti P, Patel A, DeCara J, Mitchell J, Harrison E, Moslehi J, Witteles R, Calabro MG, Orecchia R, de Azambuja E, Zamorano JL, et al. ESMO Guidelines Committee. (2020) Management of cardiac disease in cancer patients throughout oncological treatment: ESMO consensus recommendations. Annals of oncology : official journal of the European Society for Medical Oncology, 31(2), 171-190. https://doi.org/10.1016/j.annonc.2019.10.023

8. Kearney LG, Lu K, Ord M, Patel SK, Profitis K, Matalanis G, Burrell LM, Srivastava PM (2012) Global longitudinal strain is a strong independent predictor of all-cause mortality in patients with aortic stenosis. European heart journal. Cardiovascular Imaging, 13(10), 827833. https://doi.org/10.1093/ehjci/jes115

9. Reant P, Mirabel M, Lloyd G, Peyrou J, Lopez JM, Dickie S, Bulluck H, Captur G, Rosmini S, Guttmann O, Demetrescu C, Pantazis A. Tome-Esteban M, Moon JC, Lafitte S, McKenna WJ (2016) Global longitudinal strain is associated with heart failure outcomes in hypertrophic cardiomyopathy. Heart (British Cardiac Society), 102(10), 741-747. https://doi.org/10.1136/heartjnl-2015-308576

10. Sawaya H, Sebag I A, Plana JC, Januzzi JL, Ky B, Tan TC, Cohen V, Banchs J, Carver JR, Wiegers SE, Martin RP, Picard MH, Gerszten RE, Halpern EF, Passeri J, Kuter I, Scherrer-Crosbie M (2012) Assessment of echocardiography and biomarkers for the extended prediction of cardiotoxicity in patients treated with anthracyclines, taxanes, and trastuzumab. Circulation. Cardiovascular imaging, 5(5), 596-603. https://doi.org/10.1161/CIRCIMAGING.112.973321

11. Chang WT, Shih JY, Feng YH, Chiang CY, Kuo YH, Chen WY, Wu HC, Cheng JT, Wang JJ, Chen ZC (2016) The Early Predictive Value of Right Ventricular Strain in Epirubicin-Induced Cardiotoxicity in Patients with Breast Cancer. Acta Cardiologica Sinica, 32(5), 550-559. https://doi.org/10.6515/acs20151023a

12. Grover S, Leong DP, Chakrabarty A, Joerg L, Kotasek D, Cheong K, Joshi R, Joseph MX, DePasquale C, Koczwara B, Selvanayagam JB (2013) Left and right ventricular effects of anthracycline and trastuzumab chemotherapy: a prospective study using novel cardiac imaging and biochemical markers. International Journal of Cardiology, 168(6), 5465-

5467. https://doi.org/10.1016/j.ijcard.2013.07.246

13. Lang RM, Badano LP, Mor-Avi V, Afilalo J, Armstrong A, Ernande L, Flachskampf F A, Foster E, Goldstein SA, Kuznetsova T, Lancellotti P, Muraru D, Picard MH, Rietzschel ER, Rudski L, Spencer KT, Tsang W, Voigt JU (2015) Recommendations for cardiac chamber quantification by echocardiography in adults: an update from the American Society of Echocardiography and the European Association of Cardiovascular Imaging. Journal of the American Society of 
Echocardiography : official publication of the American Society of Echocardiography, 28(1), 139.e14. https://doi.org/10.1016/j.echo.2014.10.003

14. Thavendiranathan P, Negishi T, Somerset E, Negishi K, Penicka M, Lemieux J, Aakhus S, Miyazaki S, Shirazi M, Galderisi M, Marwick TH, SUCCOUR Investigators (2021) Strain-Guided Management of Potentially Cardiotoxic Cancer Therapy. Journal of the American College of Cardiology, 77(4), 392401. https://doi.org/10.1016/j.jacc.2020.11.020

15. Plana JC, Galderisi M, Barac A, Ewer MS, Ky B, Scherrer-Crosbie M, Ganame J, Sebag IA, Agler DA, Badano LP, Banchs J, Cardinale D, Carver J, Cerqueira M, DeCara JM, Edvardsen T, Flamm SD, Force T, Griffin BP, Jerusalem G, Lancellotti P (2014) Expert consensus for multimodality imaging evaluation of adult patients during and after cancer therapy: a report from the American Society of Echocardiography and the European Association of Cardiovascular Imaging. Journal of the American Society of Echocardiography: Official Publication of the American Society of Echocardiography, 27(9), 911-939. https://doi.org/10.1016/j.echo.2014.07.012

16. Melo MGT, Paiva MG, Santos MVG, Rochitte CE, Moreira VM, Saleh MH, Brandão SCS, Callafrio CC, Goldwasser D, Gripp EA et al. (2021) Brazilian Position Statement on the Use Of Multimodality Imaging in Cardio-Oncology. Arquivos Brasileiros de Cardiologia. 56. https://doi.org/10.36660/abc.20200266

17. Lange SA, Ebner B, Wess A, Kögel M, Gajda M, Hitschold T, Jung J (2012) Echocardiography signs of early cardiac impairment in patients with breast cancer and trastuzumab therapy. Clinical research in cardiology : official journal of the German Cardiac Society, 101(6), 415-426. https://doi.org/10.1007/s00392-011-0406-0

18. Calleja A, Poulin F, Khorolsky C, Shariat M, Bedard PL, Amir E, Rakowski H, McDonald M, Delgado D, Thavendiranathan P (2015) Right Ventricular Dysfunction in Patients Experiencing Cardiotoxicity during Breast Cancer Therapy. Journal of Oncology, 2015, 609194. https://doi.org/10.1155/2015/609194

19. Keramida K, Farmakis D, Bingcang J, Sulemane S, Sutherland S, Bingcang RA, Ramachandran K, Tzavara C, Charalampopoulos G, Filippiadis D, Kouris N, Nihoyannopoulos P (2019) Longitudinal changes of right ventricular deformation mechanics during trastuzumab therapy in breast cancer patients. European Journal of Heart Failure, 21(4), 529-535. https://doi.org/10.1002/ejhf.1385

20. Thavendiranathan P, Poulin F, Lim KD, Plana JC, Woo A, Marwick TH (2014) Use of myocardial strain imaging by echocardiography for the early detection of cardiotoxicity in patients during and after cancer chemotherapy: a systematic review. Journal of the American College of Cardiology, 63(25 Pt A), 2751-2768. https://doi.org/10.1016/j.jacc.2014.01.073

21. Smolarek D, Gruchała M, Sobiczewski W (2017) Echocardiographic evaluation of right ventricular systolic function: The traditional and innovative approach. Cardiology journal, 24(5), 563572. https://doi.org/10.5603/CJ.a2017.0051

22. Anavekar NS, Gerson D, Skali H, Kwong RY, Yucel EK, Solomon SD (2007) Two-dimensional assessment of right ventricular function: an echocardiographic-MRI correlative study. 
Echocardiography (Mount Kisco, N.Y.), 24(5), 452-456. https://doi.org/10.1111/j.15408175.2007.00424.x

23. Keramida K, Farmakis D (2020) Right ventricular involvement in cancer therapy-related cardiotoxicity: the emerging role of strain echocardiography. Heart failure reviews, 10.1007/s10741-020-09938-8. Advance online publication. https://doi.org/10.1007/s10741-020-09938-8

24. Merlo M, Gobbo M, Stolfo D, Losurdo P, Ramani F, Barbati G, Pivetta A, Di Lenarda A, Anzini M, Gigli M, Pinamonti B, Sinagra G (2016) The Prognostic Impact of the Evolution of RV Function in Idiopathic DCM. JACC. Cardiovascular imaging, 9(9), 10341042. https://doi.org/10.1016/j.jcmg.2016.01.027

25. Haddad F, Doyle R, Murphy DJ, Hunt SA (2008) Right ventricular function in cardiovascular disease, part II: pathophysiology, clinical importance, and management of right ventricular failure. Circulation, 117(13), 1717-1731. https://doi.org/10.1161/CIRCULATIONAHA.107.653584

26. Arciniegas Calle MC, Sandhu NP, Xia H, Cha SS, Pellikka PA, Ye Z, Herrmann J, Villarraga HR (2018) Two-dimensional speckle tracking echocardiography predicts early subclinical cardiotoxicity associated with anthracycline-trastuzumab chemotherapy in patients with breast cancer. $B M C$ cancer, 18(1), 1037. https://doi.org/10.1186/s12885-018-4935-z

27. Jerusalem G, Lancellotti P, Kim SB (2019) HER2+ breast cancer treatment and cardiotoxicity: monitoring and management. Breast cancer research and treatment, 177(2), 237250. https://doi.org/10.1007/s10549-019-05303-y

\section{Tables}

Table 1. Baseline clinical characteristics of the study population $(n=25)$. 


\begin{tabular}{ll}
\hline Age, years & $52.1 \pm 13.1$ \\
\hline Weight, $\mathrm{kg}$ & $74.3 \pm 14.8$ \\
\hline Height, $\mathrm{cm}$ & $157 \pm 5.9$ \\
\hline $\mathrm{BMl}, \mathrm{kg} / \mathrm{m}^{2}$ & $29.9 \pm 6.0$ \\
\hline SBP, $\mathrm{mmHg}$ & $130.2 \pm 18.7$ \\
\hline DBP, $\mathrm{mmHg}$ & $82.2 \pm 12.6$ \\
\hline Heart rate, bpm & $84.0 \pm 11.0$ \\
\hline eGFR, $\mathrm{mL} / \mathrm{min} / 1.73 \mathrm{~m}^{2}$ & $102.4(81.9-129.1)$ \\
\hline Hypertension & $8(32 \%)$ \\
\hline Type 2 diabetes & $3(12 \%)$ \\
\hline Smoking & $13(52 \%)$ \\
\hline Obesity (BMl>30Kg/m $\left.{ }^{2}\right)$ & $12(48 \%)$ \\
\hline Radiotherapy & $21(84 \%)$ \\
\hline Anthracyclines & $11(46 \%)$ \\
\hline Angiotensin-converting enzyme inhibitor & $5(20 \%)$ \\
\hline Beta-blockers & $5(20 \%)$ \\
\hline
\end{tabular}

** Values noted as mean \pm SD, median (IQR) or $\mathrm{N}(\%)$

BMI, body mass index; SBP, systolic blood pressure; DBP, diastolic blood pressure; eGRF, estimated glomerular filtration rate.

Table 2. Mean values of echocardiographic parameters of the baseline and follow-up. 


\begin{tabular}{lllll} 
& Exam 1 & Exam 2 & Exam 3 & Exam 4 \\
\hline LVEF, \% & $64.1 \pm 4.9$ & $61.6 \pm 6.6$ & $62.3 \pm 6.7$ & $60.9 \pm 4.9^{*}$ \\
\hline LV GLS, \% & $-20.6 \pm 2.0$ & $-19.4 \pm 2.1^{*}$ & $-19.2 \pm 1.8^{*}$ & $-19.0 \pm 2.1^{*}$ \\
\hline RV basal, mm & $34.4 \pm 4.1$ & $35.1 \pm 3.7$ & $34.9 \pm 3.0$ & $34.6 \pm 3.0$ \\
\hline TAPSE, mm & $21.9 \pm 3.0$ & $20.2 \pm 2.3$ & $20.8 \pm 3.4$ & $21.5 \pm 3.8$ \\
\hline S $^{\prime}$ wave, cm/s & $13.1 \pm 1.2$ & $12.7 \pm 2.0$ & $12.6 \pm 2.0$ & $12.5 \pm 2.1$ \\
\hline RV FAC (\%) & $44.3 \pm 6.6$ & $42.9 \pm 5.7$ & $39.9 \pm 6.0^{*}$ & $42.1 \pm 6.2$ \\
\hline RV GLS (\%) & $-23.9 \pm 1.6$ & $-22.5 \pm 2.1^{*}$ & $-22.5 \pm 2.3^{*}$ & $-23.1 \pm 2.2$ \\
\hline FW GLS (\%) & $-26.6 \pm 2.5$ & $-25.9 \pm 3.0$ & $-24.7 \pm 3.8$ & $-26.1 \pm 3.5$
\end{tabular}

Data are presented as the mean $+\mathrm{SD}$.

${ }^{\star} \mathrm{p}<0.05$ compared to Exam 1 (baseline).

Exam 1 baseline echocardiogram; Exam 2 echocardiogram performed between 3 and 6 months; Exam 3 echocardiogram performed between 6 and 9 months; Exam 4 echocardiogram performed between 9 and 12 months.

LVEF, left ventricular ejection fraction; LV GLS, left ventricular global longitudinal strain; RV, right ventricular; FAC: Fractional Area Change, TAPSE, tricuspid annular plane systolic excursion; S' wave, tricuspid annular peak systolic velocity; RV GLS, right ventricular global longitudinal strain; FW GLS, right ventricular free wall global longitudinal strain.

Table 3. Clinical characteristics in patients with and without subclinical LV cardiotoxicity. 


\begin{tabular}{|c|c|c|c|c|}
\hline Variable & $\begin{array}{l}\text { No LV subcli } \\
n=12\end{array}$ & ardiotoxicity & $\begin{array}{l}\text { LV subclinical } \\
\text { cardiotoxicity } \\
n=13\end{array}$ & P-value \\
\hline Age, years & $50.8 \pm 10.1$ & & $53.4 \pm 15.8$ & 0.633 \\
\hline Weig & & $72.4 \pm 8.0$ & $76.1 \pm 19.2$ & 0.533 \\
\hline Heig & & $155 \pm 5.1$ & $159 \pm 6.8$ & 0.097 \\
\hline BMI, & & $30.0 \pm 3.9$ & $29.8 \pm 7.6$ & 0.943 \\
\hline SBP, & & $132.4 \pm 20.7$ & $128.3 \pm 17.5$ & 0.613 \\
\hline DBP, & & $85.9 \pm 12.7$ & $79.1 \pm 12.2$ & 0.194 \\
\hline Hear & bpm & $76.5 \pm 12.2$ & $74.9 \pm 11.5$ & 0.750 \\
\hline eGFF & $/ \mathrm{min} / 1.73 \mathrm{~m}^{2}$ & $105.1 \pm 35.4$ & $118.3 \pm 56.8$ & 0.491 \\
\hline Hype & ion & $4(33 \%)$ & $4(31 \%)$ & 0.891 \\
\hline Type & betes & $1(8 \%)$ & $2(15 \%)$ & 0.588 \\
\hline Obes & & $7(58 \%)$ & $5(38 \%)$ & 0.320 \\
\hline Smo & & $7(58 \%)$ & $6(46 \%)$ & 0.543 \\
\hline ACEI & & $2(17 \%)$ & $3(23 \%)$ & 0.689 \\
\hline Beta- & ers & $3(25 \%)$ & $2(15 \%)$ & 0.548 \\
\hline Radi & apy & $11(92 \%)$ & $10(77 \%)$ & 0.315 \\
\hline $\begin{array}{l}\text { Anthracyclin } \\
\text { use }\end{array}$ & $5(42 \%)$ & & $6(46 \%)$ & 0.682 \\
\hline
\end{tabular}

** Values noted as mean $\pm \mathrm{SD}$ or $\mathrm{N}(\%)$

BMI, body mass index; SBP, systolic blood pressure; DBP, diastolic blood pressure eGRF, estimated glomerular filtration rate; ACEI/ARB, angiotensin-converting enzyme inhibitors/angiotensin receptor blockers.

Table 4. Echocardiographic baseline parameters in patients with subclinical cardiotoxicity and without subclinical cardiotoxicity 


\begin{tabular}{|c|c|c|c|}
\hline \multirow[t]{2}{*}{ Variable } & $\begin{array}{l}\text { No LV subclinical } \\
\text { cardiotoxicity }\end{array}$ & $\begin{array}{l}\text { LV subclinical } \\
\text { cardiotoxicity }\end{array}$ & \multirow[t]{2}{*}{ P-value } \\
\hline & & $n=13$ & \\
\hline LV diastolic diameter, $\mathrm{cm}$ & $45.3 \pm 2.7$ & $50.5 \pm 3.2$ & 0.0002 \\
\hline LV systolic diameter, cm & $29.5 \pm 2.5$ & $32.7 \pm 4.1$ & 0.027 \\
\hline Septal wall thicknesses, cm & $8.0 \pm 0.7$ & $8.5 \pm 1.0$ & 0.214 \\
\hline $\begin{array}{l}\text { Posterior wall thicknesses, } \\
\mathrm{cm}\end{array}$ & $7.7 \pm 0.5$ & $8.1 \pm 1.0$ & 0.188 \\
\hline LV Diastolic Volume, mL & $86.6 \pm 16.6$ & $112.0 \pm 31.7$ & 0.02 \\
\hline LV Systolic Volume, mL & $37.6 \pm 12.1$ & $49.6 \pm 15.2$ & 0.039 \\
\hline LVEF, \% & $64.2 \pm 4.4$ & $64.0 \pm 5.5$ & 0.934 \\
\hline LA diameter, cm & $34.8 \pm 3.9$ & $36.9 \pm 4.7$ & 0.222 \\
\hline LA volume, $\mathrm{mL}$ & $52.1 \pm 11.2$ & $62.5 \pm 22.9$ & 0.191 \\
\hline$E / e^{\prime}$ mean & $8.4 \pm 2.1$ & $7.9 \pm 2.9$ & 0.666 \\
\hline $\begin{array}{l}\text { Transtricuspid gradient, } \\
\mathrm{mmHg}\end{array}$ & $23.2 \pm 7.9$ & $24.9 \pm 4.6$ & 0.723 \\
\hline RV basal, mm & $34.3 \pm 3.7$ & $34.5 \pm 4.5$ & 0.938 \\
\hline TAPSE, mm & $21.7 \pm 2.6$ & $22.1 \pm 3.5$ & 0.771 \\
\hline $\mathrm{S}^{\prime}$ wave, $\mathrm{cm} / \mathrm{s}$ & $13.6 \pm 0.9$ & $12.7 \pm 1.3$ & 0.116 \\
\hline RV FAC, \% & $44.7 \pm 6.9$ & $43.9 \pm 6.5$ & 0.79 \\
\hline RV GLS, \% & $-23.8 \pm 1.8$ & $-24.1 \pm 1.4$ & 0.662 \\
\hline FW GLS, \% & $-26.4 \pm 2.8$ & $-26.8 \pm 2.3$ & 0.740 \\
\hline
\end{tabular}

Data are presented as the mean + SD.

LVEF, left ventricular ejection fraction; LA: left atrial; RV, right ventricular; FAC: Fractional Area Change, TAPSE, tricuspid annular plane systolic excursion; S' wave, tricuspid annular peak systolic velocity; RV GLS, right ventricular global longitudinal strain; FW GLS, right ventricular free wall global longitudinal strain.

\section{Figures}



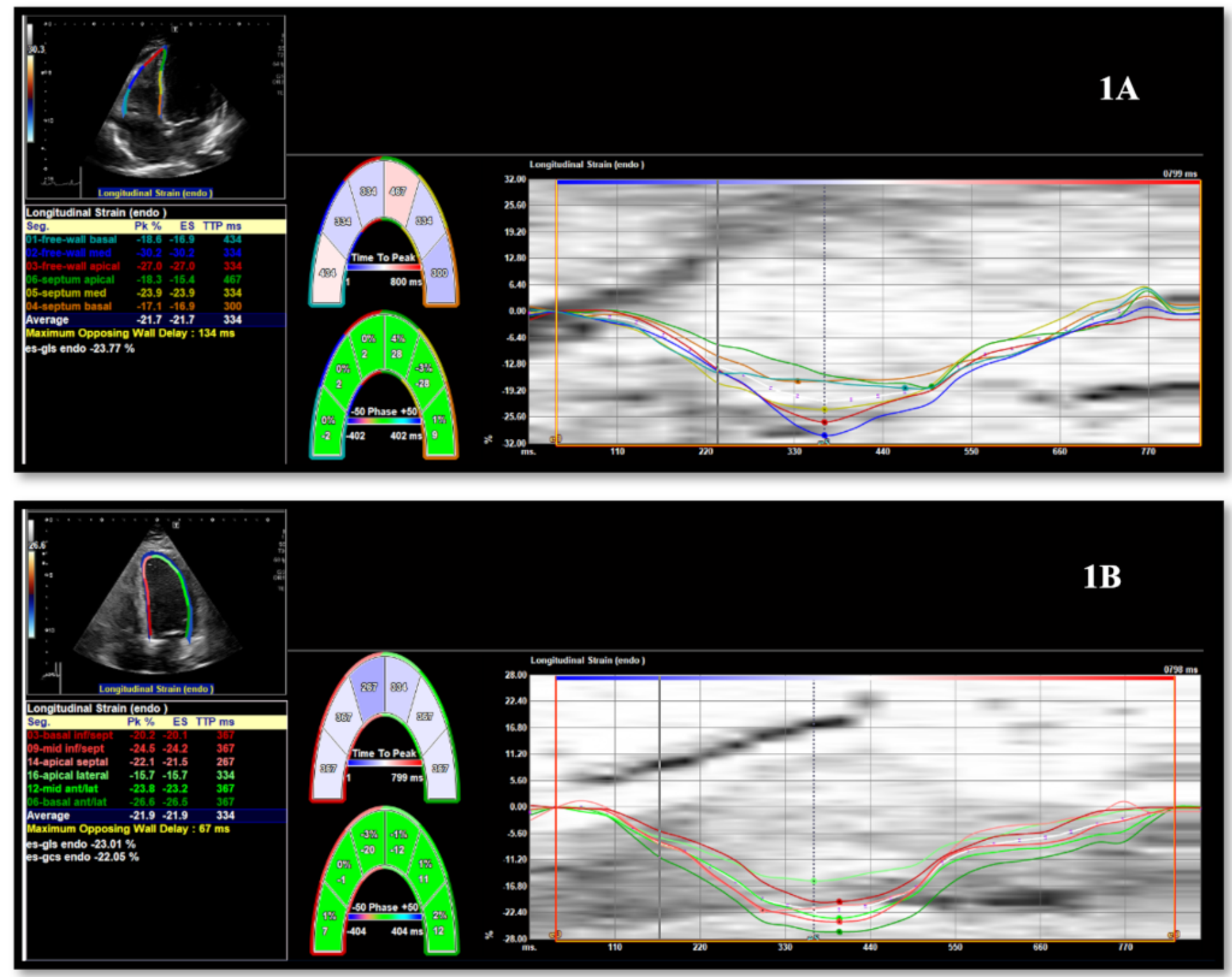

\section{Figure 1}

Right ventricle global longitudinal strain (Figure 1A) and left ventricle global longitudinal strain (Figure 1B). 
$2 \mathrm{~A}$
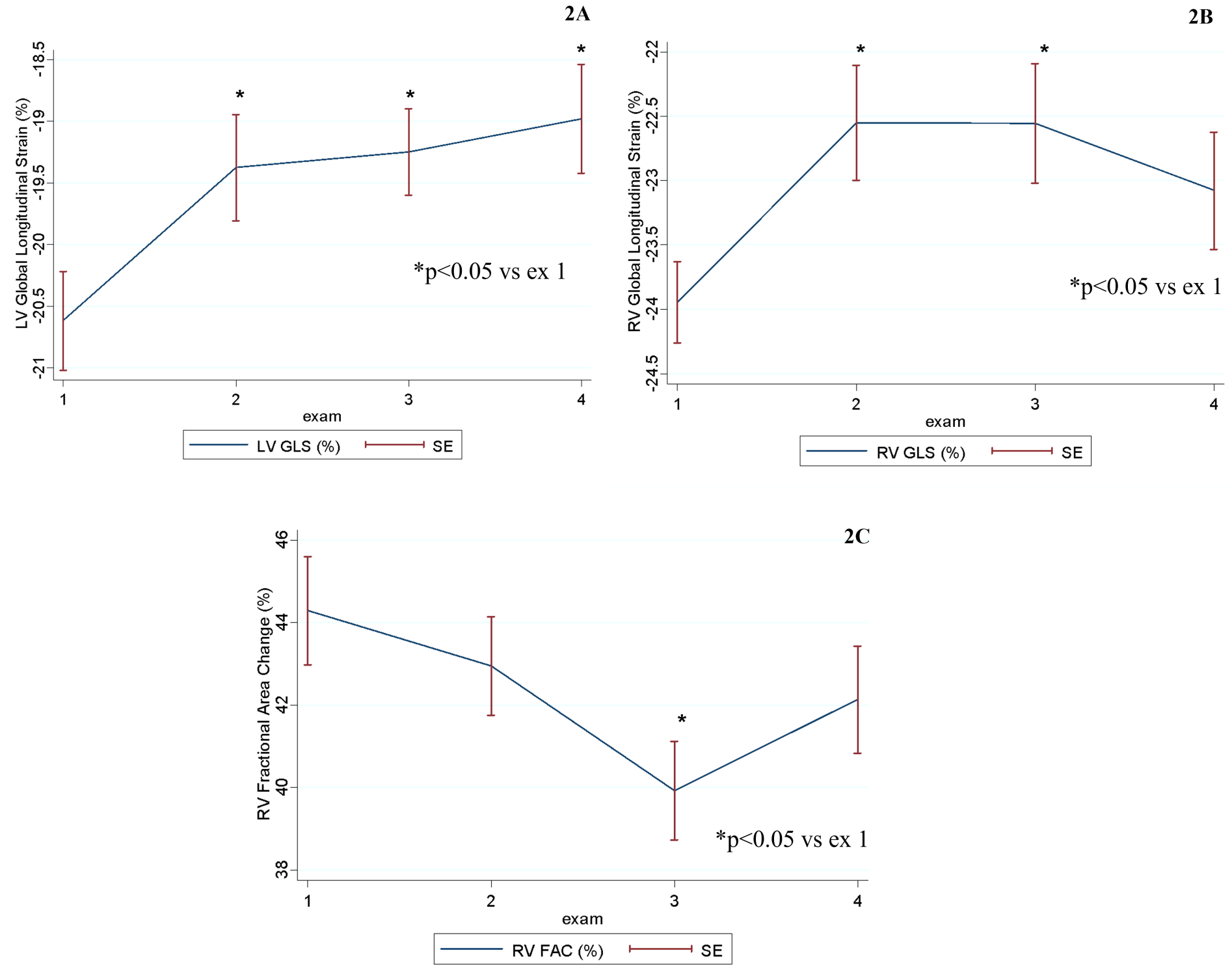

\section{Figure 2}

Mean values of left ventricular global longitudinal strain (figure 2A), right ventricular global longitudinal strain (figure 2B) and right ventricular fractional area change (figure $2 \mathrm{C}$ ) during trastuzumab therapy. 
3A
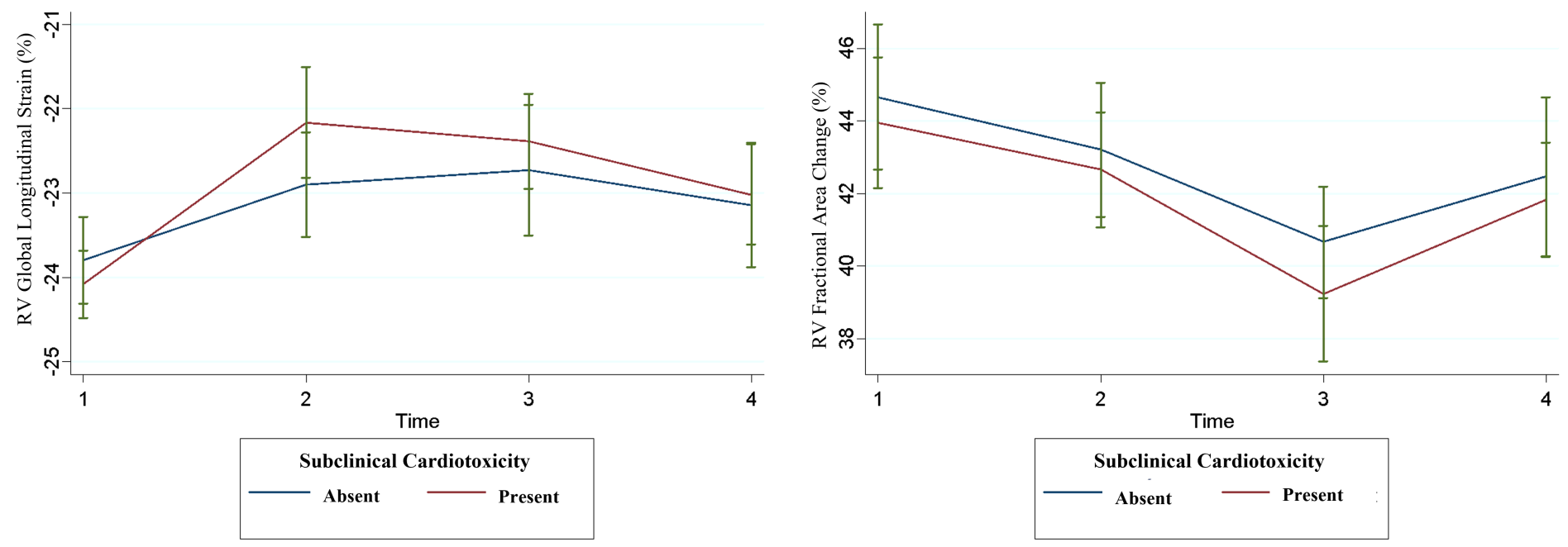

Figure 3

Mean values of right ventricular global longitudinal strain (figure $3 \mathrm{~A}$ ) and right ventricular fractional area change (figure $3 \mathrm{~B}$ ) during trastuzumab therapy in patients with subclinical cardiotoxicity and without subclinical cardiotoxicity. 